Tropical Journal of Pharmaceutical Research November 2017; 16 (11): 2755-2760

ISSN: $1596-5996$ (print); 1596-9827 (electronic)

(c) Pharmacotherapy Group, Faculty of Pharmacy, University of Benin, Benin City, 300001 Nigeria.

All rights reserved.

Available online at http://www.tjpr.org

Original Research Article

http://dx.doi.org/10.4314/tjpr.v16i11.25

\title{
Treatment responses in adult depressive patients treated with dexamethasone/corticotrophin-releasing hormone
}

\author{
Lina Zhang ${ }^{1 \star}$, Yanbo Chen ${ }^{2}$, Guoqing Sun ${ }^{1}$, Lei Zhang ${ }^{1}$, Defeng $\mathrm{Hu}^{1}$ and $\mathrm{Wu}$ \\ Zhe $^{1}$ \\ ${ }^{1}$ Department of Psychiatry, ${ }^{2}$ The Medical Services Section, The Seventh People's Hospital of Hangzhou, Zhejiang Province, \\ China, 310013
}

*For correspondence: Email: linazhang0@hotmail.com; Tel/Fax: 0086-18758043379

Sent for review: 25 May 2017

Revised accepted: 13 October 2017

\begin{abstract}
Purpose: To study the dexamethasone/corticotrophin releasing hormones (DEX/CRH) in depressed and healthy patients and to analyse the occurrence of relapse connected to hormonal dysregulation. Methods: A total of 117 depressive patients between 20 and 70 years of age were included in the study group and 40 healthy patients between 25 and 60 years of age in the control group. Group I consisted of 59 patients who received sertraline $50-100 \mathrm{mg} /$ day for 5 weeks along with a low dose of $30 \mathrm{mg}$ T3. Group II included 58 patients who received dexamethasone $1 \mathrm{mg}$ orally for 5 weeks. DEX/CRH levels were analyzed. Adrenocorticotrophic hormone and cortisol levels in the blood were analysed by immuno-radiometric assay. Cortisol levels were also analysed by kinetic assay method.

Results: In group l, among the 59 patients that received sertraline 50-100 mg/day for 5 weeks with a low dose of $30 \mathrm{mg} \mathrm{T3}$, relapse was observed in $12(20.3 \%)$ of them. The area under the curve (AUC) was $13.9 \pm 6.4 \mathrm{ng} . \mathrm{min} .1000 / \mathrm{mL}$, which was higher than that for healthy individuals $(3.8 \pm 3.6$ ng.min. $1000 / \mathrm{mL}$ ). Group I patients with relapse showed an adrenocorticotrophic hormone AUC of $16.9 \pm$ $2.4 \mathrm{ng} . \mathrm{min} .1000 / \mathrm{mL}$, while group II patients exhibited AUC of $13.9 \pm 6.4 \mathrm{ng} \cdot \mathrm{min} .1000 / \mathrm{mL}$.

Conclusion: The results emphasizes the need to test hormonal responses to different types of antidepressants.
\end{abstract}

Keywords: stress, depressive patients, hormonal response, hormonal dysregulation, sertraline, dexamethasone, corticotrophin releasing hormone

Tropical Journal of Pharmaceutical Research is indexed by Science Citation Index (SciSearch), Scopus, International Pharmaceutical Abstract, Chemical Abstracts, Embase, Index Copernicus, EBSCO, African Index Medicus, JournalSeek, Journal Citation Reports/Science Edition, Directory of Open Access Journals (DOAJ), African Journal Online, Bioline International, Open-J-Gate and Pharmacy Abstracts

\section{INTRODUCTION}

Depression is a severe psychiatric disorder involving multiple etiological factors such as the surrounding environment and genetics [1]. The main precipitating factor in depression is stress, which can be treated with antidepressants [2-5]. Many researchers have reported clear evidence of altered endocrine factors and dysregulation of metabolism due to mood disorders [6].

There is no single marker that is linked to depre- ssive disorders. Many studies have reported a link between hormonal abnormalities and depressive disorders, and the combination of dexamethasone/corticotrophin releasing hormones $(\mathrm{DEX} / \mathrm{CRH})$ is a known indicator of hypothalamic, pituitary, and adrenal system function [7]. Previous studies have shown a link between the hypothalamic-pituitary-thyroid hormonal axis and depression. Low levels of thyroid stimulating hormone (TSH) are observed in patients with depression [8,9]. Most studies have focused on developing a test to determine 
the function of the hypothalamic-pituitary-thyroidadrenocorticol system because it plays an essential role in regulating corticotrophin releasing hormone, which impacts patients with depression. Based on these results, antidepressant therapeutics have been developed to overcome this disorder among depressed patients [10].

Depressive patients' urine and plasma have high levels of free cortisol [11]. It seems that depression leads to the release of increased levels of corticotropin-releasing hormone in cerebrospinal fluid [12] and reduced levels of adrenocorticotrophic hormone after administration of antidepressants. Our study was designed to determine the responses to the use of antidepressants. We used a highly sensitive test to detect altered hypothalamic-pituitarythyroid-adrenocorticol hormone regulation. We also focused on evaluating stress paradigms, such as cold pressor and mental arithmetic, and their effect on DEX/CRH levels in depressed and healthy patients with stress due to other reasons, such as illness or disorder. We also analysed the occurrence of relapse with respect to hormonal dysregulation.

\section{METHODS}

\section{Study setting}

The study was carried out in Department of Psychiatry, The Medical Services Section and The Seventh People's Hospital of Hangzhou, Zhejiang Province, China, during the period of March 2015 to March 2017. The Institutional Ethical Board of The Seventh People's Hospital of Hangzhou, Zhejiang Province, China approved the study with ref number SPHH 144-14/15. The study was conducted after obtaining the informed consent from patient's or guardian.

\section{Subjects}

A total of 117 patients between 20 to 70 years of age were included in the study.40 control group patients in the age of 25 to 60 years of age who are with stress due to illness and disorders were included in the study. The study group patients were categorised based on the structural clinical interview for DSM - IV Axis I Disorder [13]. For most of the patients, Hamilton Rating Scale of depression score was between 16 and 17 before the therapy was initiated.

\section{Study design}

The inclusion criteria were hospitalised patients, age > 20 years, and both male and female gender, while the exclusion criteria were patients $<20$ years, patients on drug or alcohol, and pregnant women.

All the patients, both in the study group and the control group, were divided into 2 groups. Group I consisted of 59 patients who received sertraline $50 \mathrm{mg} /$ day. They were given Sertraline for 5 weeks to assess the improvement in patient's condition. If the patients did not respond the dosage were increased to $100 \mathrm{mg} /$ day. Group I patients were also given low dose of $30 \mathrm{mg}$ of T3. The prognosis of the patients was assessed based on the Hamilton Rating Scale for Depression (HRSD) score. Reduction of more than $50 \%$ was taken as good prognosis. All the 59 patients were followed for 5 weeks to 18 months to observe for any relapse and improvement in the depression state. Twenty control group patients were assessed by cold pressor test and mental arithmetic calculation for a fixed time.

Group II included 58 patients who received Dexamethasone $1 \mathrm{mg}$ orally. They were assessed for 5 weeks to observe the prognosis of patient's mental health condition. DEX / CRH test were done. Global Assessment finding were done at end of every $2^{\text {nd }}$ week. No hormone was given before starting the therapy in group II patients. Patients who had relapse were also followed up with factors taken into consideration such as time taken for relapse, duration of relapse and dosage of treatment in the patients were assessed.

All the assessments were done by trained Psychiatrist. The scale of rating depressed followed in our study was the Hamilton Anxiety Rating Scale [13].

\section{Parameters for analysis of stress}

These parameters were measured to analyse 40 healthy control group patients (20 in group I and 20 in group II) to estimate their level of stress.

\section{Cold therapy}

Cooling water was used. The patients were asked to soak their feet in cool water for $3 \mathrm{~min}$ and asked to keep out for 2 min which was repeated for 10 times for 50 mins.

\section{Mental arithmetic}

Random numbers projected on the slide were shown to the healthy individuals with illness and disorders. They have to calculate the number randomly by adding, subtracting, multiplying and 
dividing. A time limit of $15 \mathrm{~s}$ was given to complete the task. The task was repeated for 5 times with $10 \mathrm{~s}$ interval for $10 \mathrm{~min}$.

\section{Thyroid-releasing hormone test}

Patients in both groups were kept in fasting on the day of blood collection after 1.5 weeks of treatment. Blood samples were collected to assess the TSH level. After which $0.75 \mathrm{mg}$ of $\mathrm{TRH}$ was given IV route and blood were collected at $30 \mathrm{~min}, 1$ and $1.5 \mathrm{~h}$ time intervals to assess the level of TSH in blood. Maximum TSH value was determined.

\section{Hormonal assessment test}

One milligram of dexamethasone was given orally. DEX/CRH test was done on the same day of assessing TSH levels. Blood samples were collected at the interval of $30 \mathrm{~min}, 1$ and $1.5 \mathrm{~h}$ to assess the ACTH and Cortisol levels in blood. After blood collection $\mathrm{CRH} 75 \mu \mathrm{g}$ were given by IV route. Again blood samples were collected at $30 \mathrm{~min}, 45 \mathrm{~min}, 1 \mathrm{~h}$ and $1.5 \mathrm{~h}$ interval. A total of 8 $\mathrm{mL}$ blood was collected to measure ACTH (pmol / L) and cortisol levels (nmol / L) in the blood. ACTH levels were analysed by Immunoradiometric assay. Cortisol Level were also analysed by Kinetic assay method. All the parameters and test were analysed with respect to age, gender and BMI, depression scores, etc.

\section{Statistical analysis}

Statistical analysis was done by Fischer's exact test and Mann-Whitney $U$ tests using SPSS software version 21.0. T-test was calculated to determine the hormonal test data against age and sex of the patients. Correlation coefficient of association was analysed based on the Recurrence and responding nature of the patients. Statistical significance was set at $p>$ 0.001 .

\section{RESULTS}

Out of 117 patients included in our study, 62 $(52.9 \%)$ were female and $55(47.1 \%)$ were male; all of the patients were $20-70$ years old, with a mean age of $42.8 \pm 4.5$ years. All of the demographic details, such as age, gender, family history, relapse, duration of hospital stay, prior treatment received, and dose of antidepressant taken, were obtained from hospital records. Of the 40 healthy control group patients, 25 (62.5 $\%)$ were male and $15(37.5 \%)$ were female. The control group patients were $25-60$ years of age, with a mean age of $52.1 \pm 3.8$ years. There were no differences based on age, but female patients required longer stays than male patients in both the study group and in the control group. A significant difference was observed in the number of relapses and in hormonal responses between the groups. Differences were considered statistically significant when $p>$ 0.001 (present study, $p=0.013$; Table 1).

Table 1: Demographic profile of the patients

\begin{tabular}{|c|c|c|c|}
\hline Parameter & Group I & Group II & Control \\
\hline $\begin{array}{l}\text { Age } \\
\text { (years) } \\
\text { Sex }\end{array}$ & $44.9 \pm 5.6$ & $47.2 \pm 4.2$ & $52.1 \pm 3.8$ \\
\hline $\begin{array}{l}\text { Male } \\
\text { Female }\end{array}$ & $\begin{array}{l}20 \\
(33.9 \%) \\
39 \\
(66.1 \%)\end{array}$ & $\begin{array}{l}35(60.3 \%) \\
23(39.6 \%)\end{array}$ & $\begin{array}{l}25 \\
(62.5 \%) \\
15 \\
(37.5 \%)\end{array}$ \\
\hline $\begin{array}{l}\text { Past family } \\
\text { history of } \\
\text { Relapse }\end{array}$ & $8(\%)$ & $4(\%)$ & $1(\%)$ \\
\hline $\begin{array}{l}\text { Duration of } \\
\text { hospital } \\
\text { stay }\end{array}$ & $\begin{array}{l}\text { Males: } \\
12 \text { weeks } \\
\text { Females: } \\
20 \text { weeks }\end{array}$ & $\begin{array}{l}\text { Males: } 7 \text { weeks } \\
\text { Females: } 16 \\
\text { weeks }\end{array}$ & $\begin{array}{l}\text { Males: } 5 \\
\text { weeks } \\
\text { Females: } \\
14 \\
\text { weeks }\end{array}$ \\
\hline $\begin{array}{l}\text { HAMD } \\
\text { score }\end{array}$ & $22.1 \pm 4.1$ & $22.4 \pm 5.3$ & $17.1 \pm 3.3$ \\
\hline $\begin{array}{l}\text { Treatment } \\
\text { received }\end{array}$ & Sertraline & Dexamethasone & Both \\
\hline $\begin{array}{l}\text { Duration of } \\
\text { dosage }\end{array}$ & $\begin{array}{l}5 \text { weeks } \\
\text { for } 18 \\
\text { months }\end{array}$ & $\begin{array}{l}5 \text { weeks for } 18 \\
\text { months }\end{array}$ & $\begin{array}{l}5 \text { weeks } \\
\text { for } 18 \\
\text { months }\end{array}$ \\
\hline $\begin{array}{l}\text { T3 } \\
\text { addition }\end{array}$ & 59 & - & - \\
\hline
\end{tabular}

Among the 59 group I patients with depression, $39(66.1 \%)$ were female and $20(33.9 \%)$ were male. These patients were $40-65$ years of age, with a mean age of $44.9 \pm 5.6$ years. Among the control group patients, $12(60 \%)$ were female and $8(40 \%)$ were male; the age rage was 3558 years, with a mean age of $46.5 \pm 6.7$ years. Of the group I patients who received sertraline 50-100 mg/day for 5 weeks followed by 18 months of a low dose of $30 \mathrm{mg} \mathrm{T3}$, only 12 showed relapse $(20.3 \%)$. A total of $23(38.9 \%)$ patients showed relapse within 18 months of the study. All of the 59 group I patients strictly adhered to the medication regime. Only two of the patients had poor compliance, which we resolved by giving instructions to the patient's family members. Tension and anxiety were assessed in 20 healthy patients performing tasks such as the cold pressor and mental arithmetic calculations. We recorded the time required to complete the tasks and found significant differences $(p=0.011)$. When Task I and Task II were compared, the score was significantly reduced between time intervals. The change in score was observed when patients were given time to relax between tasks. This change was significant $(p<0.01)$. The hormone levels in both 
Table 2: DEX/CRH test between relapse and non-relapse patients

\begin{tabular}{|c|c|c|c|c|}
\hline \multirow[t]{2}{*}{ Parameter } & \multicolumn{2}{|l|}{ Relapse } & \multicolumn{2}{|l|}{ No relapse } \\
\hline & Group I & Group II & Group I & Group II \\
\hline $\begin{array}{l}\text { DEX cortisol level before treatment with } \\
\text { dexamethasone }\end{array}$ & $34.8 \pm 26.9$ & $36.5 \pm 18.9$ & $44.7 \pm 42.3$ & $43.7 \pm 41.8$ \\
\hline ACTH level (ng/L) & $16.9 \pm 2.4$ & $13.9 \pm 6.4$ & $11.5 \pm 3.8$ & $12.7 \pm 4.3$ \\
\hline Cortisol level (nmol/L) & $298 \pm 161.4$ & $268 \pm 124.9$ & $214.4 \pm 140.2$ & $210.8 \pm 137.3$ \\
\hline Elevated level (n) & 12 & 18 & 47 & 40 \\
\hline AUC value $\mathrm{mg} \mathrm{h} / \mathrm{L}$ & $24.1 \pm 22.8$ & $23.4 \pm 20.9$ & $3.8 \pm 3.6$ & $4.8 \pm 2.9$ \\
\hline
\end{tabular}

the study and the control groups were elevated between $30 \mathrm{~min}$ and $1 \mathrm{~h}$ (Table 2).

Group II included 58 patients; 23 (39.6\%) were female and $35(60.3 \%)$ were male. The mean age was $47.2 \pm 4.2$ years. Among the 20 control group patients, 7 (35\%) were female and 13 (65 $\%)$ were male, with a mean age of $39.6 \pm 2.4$ years. The study group patients received $1 \mathrm{mg}$ dexamethasone orally for 5 weeks. In both the study and control groups, female patients with Hamilton Rating Scale for Depression (HAM-D) scores of 17 were hospitalized longer than male patients with the same scores.

The cortisol response among the group II patients who received dexamethasone $1 \mathrm{mg}$ was increased compared with that among the group I patients who received sertraline with T3. The area under the time-course curve (AUC) was $13.9 \pm 6.4 \mathrm{ng} \times \min \times 1000 / \mathrm{ml}$, which was higher than the AUC for healthy individuals, which was only $3.8 \pm 3.6 \mathrm{ng} \times \min \times 1000 / \mathrm{ml}(p$ $<0.01$ ).

Multiple logistic regression analysis with the AUC of the cortisol response as the dependent variable and age and severity of depression as independent variables revealed statistical significance $(p<0.01)$. The patients in both group I and group II who did not have relapse continued the treatment for 18 months; however, $18(13.8 \%)$ patients in group II had relapse.

After treatment to correct ACTH and cortisol levels, $\mathrm{DEX} / \mathrm{CRH}$ levels were measured in the relapse patients and non-relapse patients. The ACTH and cortisol levels were found to be high in group I patients who had relapse, with an AUC of $16.9 \pm 2.4 \mathrm{ng} \times \min \times 1000 / \mathrm{mL}$; whereas in group II, the AUC was less at $13.9 \pm 6.4 \mathrm{ng} \times \min$ $\times 1000 / \mathrm{mL}$, because the group II patients received $1 \mathrm{mg}$ dexamethasone before starting therapy. The risk of relapse was 3.98 (95\% Cl: 0.85-2.63). In the group 1 patients who did not have relapse, the cortisol level was $214.4 \pm$ $140.2 \mathrm{nmol} / \mathrm{L}$, whereas the cortisol level was 298 $\pm 161.4 \mathrm{nmol} / \mathrm{L}$ in the patients who had relapse. The cortisol level was found to be the most important factor for the $\mathrm{DEX} / \mathrm{CRH}$ test response. There was a significant difference between the relapse patients and the non-relapse patients ( $p$ $=0.01$; Table 2).

\section{DISCUSSION}

Our study compared the results of the DEX/CRH and $\mathrm{TRH}$ tests in patients with depression in both group I and group II. Out of 117 patients, only 41 patients showed relapse within 2 years of discharge. Our study showed that the age and body mass index of the patients had no effect on the $\mathrm{ACTH} / \mathrm{CRH}$ or $\mathrm{TSH}$ levels with respect to hypothalamic-pituitary-adrenal or hypothalamicpituitary-thyroid changes in depressed persons. Our study results are consistent with those of other studies, which previously reported no changes in hormonal responses to the DEX/CRH test with respect to age [14]. Heuser et al and Kudielka et al $[15,16]$ reported significant hormonal changes with age, but those studies were performed with healthy individuals. In our study, we did not see any changes in $\mathrm{DEX} / \mathrm{CRH}$ and $\mathrm{TRH}$ levels because relapse might not be associated with age factors.

We found significant differences in hormonal changes to the $\mathrm{DEX} / \mathrm{CRH}$ and $\mathrm{TRH}$ levels between male and female patients. Female patients were hospitalized for longer periods than males. Our study is similar to those by Kunugi et al, Kunzel et al, and Heuser et al $[14,17,18]$, who reported similar differences in hormonal responses to the $\mathrm{DEX} / \mathrm{CRH}$ test. Our study showed that the $\mathrm{TRH}$ response in patients with smaller AUC values was mainly in female patients rather than in male patients. A previous study by Kunzel et al [14] reported peak hormonal changes in women rather than in men when the $\mathrm{TRH}$ test was performed, which agrees with the female preponderance observed in our study.

Our study showed significant changes in the AUCs of ACTH and cortisol depending on the antidepressant used for treatment, although the HAM-D and GAF scores remained the same. Previous studies by Rybakowski and 
Twardowska et al [19] showed no changes in the $\mathrm{DEX} / \mathrm{CRH}$ test with the hypothalamic-pituitaryadrenal axis in depressive patients, which is consistent with our results.

Carpenter et al reported that DEX/CRH tests with elevated cortisol levels should not be used as biomarkers to identify depression. In our study, relapse and DEX/CRH levels were significantly correlated. Relapse patients showed varied ACTH AUC levels compared with non-relapse patients, which is in agreement with study a by Hatzinger et al [20] of the correlation between $\mathrm{DEX} / \mathrm{CRH}$ and recurrence of depression.

Many researchers have reported that supplementing T3 before treatment was effective in controlling depression. Our study also supports the administration of T3 before therapy because, in some patients, depression occurs because of TRH deficiency, which can be avoided with T3 supplementation [21].

\section{Limitations of the study}

This study was limited to a small patient population. We studied only patients with general depression and did not categorize the patients based on particular depressive conditions. Further research to find markers to detect relapse is needed with larger sample sizes and more focus on different depressive conditions. Only two antidepressants were tested in our study. Further studies are required to assess the actions of different antidepressants on hormonal responses.

\section{CONCLUSION}

The findings of this study emphasizes the need to test hormonal responses to different types of antidepressants. Further studies using different antidepressants are required to ascertain the action of antidepressants on hormonal responses. There is also the need for similar studies in large population groups.

\section{DECLARATIONS}

\section{Acknowledgement}

None provided.

\section{Conflict of Interest}

No conflict of interest associated with this work.

\section{Contribution of Authors}

The authors declare that this work was done by the authors named in this article and all liabilities pertaining to claims relating to the content of this article will be borne by them.

\section{Open Access}

This is an Open Access article that uses a funding model which does not charge readers or their institutions for access and distributed under the terms of the Creative Commons Attribution License (http://creativecommons.org/licenses/by/ 4.0) and the Budapest Open Access Initiative (http://www.budapestopenaccessinitiative.org/rea d), which permit unrestricted use, distribution, and reproduction in any medium, provided the original work is properly credited.

\section{REFERENCES}

1. Uher $R$. The implications of gene-environment interactions in depression: will cause inform cure. Mol Psychiatry 2008; 12: 1070-1078.

2. Pittenger $C$, Duman RS. Stress, depression, and neuroplasticity: a convergence of mechanisms. Neuropsycho Pharmacol 2008; 1: 88-109.

3. Calabrese F, Molteni R, Racagni G, Riva MA. Neuronal plasticity: a link between stress and mood disorders. Psychoneuro Endocrinol 2009; 34: S208-S216.

4. Castre n E, Voikar V, Rantamaki T. Role of neurotrophic factors in depression. Curr Opin Pharmacol 2007; 7: 1821.

5. Krishnan $V$, Nestler EJ. The molecular neurobiology of depression. Nature 2008; 455: 894-902.

6. Hendrickx H, McEwen BS, Ouderaa F. Metabolism, mood and cognition in aging: the importance of lifestyle and dietary intervention. Neurobiol Aging 2005; 26: 1-5.

7. Holsboer-Trachsler E, Stohler R, Hatzinger M. Repeated administration of the combined dexamethasone human corticotrophin releasing hormone stimulation test during treatment of depression. Psychiatr Res 1991; 38: 163171.

8. Prange Jr AJ, Lara PP, Wilson IC, Alltop LB, Breese GR. Effects of thyrotropin-releasing hormone in depression. Lancet 1972; 2: 999-1002.

9. Kastin AJ, Ehrensing RH, Schalch DS, Anderson MS. Improvement in mental depression with decreased thyrotropin response after administration of thyrotropinreleasing hormone. Lancet 1972; 2: 740-742.

10. Zobel AW, Nickel T, Kunzel HE, AckIN, Sonntag A, Ising $M$, Holsboer $F$. E $\square$ ects of the high-a $\square$ nity corticotropinreleasing hormone receptor 1 antagonist $R 121919$ in major depression: the first 20 patients treated. J Psychiatric Res 2000; 34: 171-181. 
11. Sachar J, Finkelstein J, Hellman L. Growth hormone responses in repressive illness response to Insulin Tolerance Test. Arch Gen Psychiatr 1971; 25: 263-269.

12. Nemeroff B. New directions in the development of antidepressants: the interface of neurobiology and psychiatry 2002; 17: 13-16

13. Hamilton. Diagnosis and rating of anxiety. Br J Psychiatr 1969; 3: 76-79

14. Künzel HE, Binder EB, Nickel $T$, Ising $T M$, Fuchs $B$, Majer M. Pharmacological and non-pharmacological factors influencing hypothalamic-pituitary-adrenocortical axis reactivity in acutely depressed psychiatric inpatients, measured by the Dex-CRH test. Neuro psycho pharmacol 2003; 28: 2169-2178.

15. Heuser I, Yassouridis A, Holsboer F. The combined dexamethasone/CRH test: a refined laboratory test for psychiatric disorders. J Psychiatr Res 1994a; 28: 341356.

16. Kudielka BM, Schmidt-Reinwald AK, Hellhammer DH, Kirschbaum C. Psychological and endocrine responses to psychosocial stress and dexamethasone/ corticotropin-releasing hormone in healthy postmenopausal women and young controls: the impact of age and a two-week estradiol treatment. Neuroendocrinol 1999; 70: 422-430
17. Kunugi $H$, Ida I, Owashi $T$, Kimura $M$, Inoue $Y$, Nakagawa S. Assessment of the dexamethasone/CRH test as a state dependent marker for hypothalamic-pituitaryadrenal (HPA) axis abnormalities in major depressive episode: a Multi-center Study. Neuro psycho pharmacol 2006; 31: 212-220.

18. Heuser IJ, Schweiger U, Gotthardt U, Schmider J, Lammers $\mathrm{CH}$, Dettling, M. Pituitary-adrenal-system regulation and psychopathology during amitriptyline treatment in elderly depressed patients and normal comparison subjects. Am J Psychiatr 1996; 153: 93-99.

19. Rybakowski JK, Twardowska K. The dexamethasone/ corticotropin-releasing hormone test in depression in bipolar and unipolar affective illness. J Psychiatr Res 1999; 33: 363-370.

20. Hatzinger M, Hemmeter UM, Baumann K, Brand $S$, Holsboer TE. The combined DEX-CRH test in treatment course and long-term outcome of major depression. $J$ Psychiatr Res 2002; 36: 287-297.

21. Cooper Kazaz R, Apter JT, Cohen R, Karagichev L, Muhammed MS, Grupper D. Combined treatment with sertraline and liothyronine in major depression: a randomized, double-blind, placebo-controlled trial. Arch Gen Psychiatry 2007; 64: 679-688. 